\title{
Effect of eccentric overload through isoinertial technology in basketball players
}

\section{Efeito da sobrecarga excêntrica através da tecnologia isoinercial em jogadores profissionais de basquetebol}

\author{
Ruben Cabanillas \\ (D) https://orcid.org/0000-0001-6388-4761 \\ Jorge Serna ${ }^{1}$ \\ (1D) https://orcid.org/0000-0002-5454-9790 \\ Veronica Muñoz-Arroyave ${ }^{1}$ \\ (1D) https://orcid.org/0000-0001-7202-8596 \\ José Albeiro Echeverri Ramos ${ }^{2}$ \\ (D) https://orcid.org/0000-0001-7454-6194
}

Abstract - The present study investigated the effect of eccentric overload on professional basketball players. Participants were 8 players aged 18-25 years who play in a Leb Oro League team. There was an 8 week training cycle with 1 weekly session of half squats. The control group performed training following a traditional methodology -using free weights- whereas the experimental group used inertial technology, that is, the ProSquat machine from Proinertial ${ }^{\circledR}$. Both vertical jump and 30 -meter sprint were assessed before and after intervention. The following conclusions were reached: a) strength training with vertical vector improves the 30 -meter sprint test and also the vertical jump; b) training program that affects the eccentric overload of the movement results in more improvements than traditional training with the same duration; c) training in the vertical vector also has an impact on the way force is manifested in the horizontal vector, showing improvements in the 30-meter sprint.

Key words: Basketball; Countermovement jump; Sprint.

Resumo - O presente estudo investigou o efeito da sobrecarga excêntrica em jogadores profissionais de basquetebol. Os participantes foram 8 jogadores de uma equipe da Leb Gold League entre 18 e 25 anos. Um ciclo de treinamento de 8 semanas foi realizado com 1 sessão semanal no exercício de meio agachamento. O grupo controle realizou o treinamento com metodologia tradicional, com pesos livres, $e$ o grupo experimental, por meio de tecnologia inercial, com a máquina ProSquat, Proinertial ${ }^{\circledR}$. O salto vertical e o sprint de 30 metros foram avaliados antes e após a intervenção. As seguintes conclusões foram obtidas: a) o treinamento de força com um componente no vetor vertical mostra melhorias no teste de 30 metros e no salto vertical; b) um programa que afeta a sobrecarga de movimento excêntrico apresenta resultados com melhores desempenhos do que o treinamento tradicional; c) o treinamento no vetor vertical também afeta uma expressão da força no vetor horizontal, mostrando melhorias no sprint de 30 metros.

Palavras-chave: Basquetebol; Salto vertical; Velocidade.
1 National Institute of Physical Education of Catalonia. University of Lleida Spain.

2 University Institute of Physical Education. University of Antioquia. Medellin Colombia.

Received: October 20, 2018 Accepted: January 23, 2020

How to cite this article Cabanillas R, Serna J, MuñozArroyave V, Echeverri A. Effect of eccentric overload through isoinertial technology in basketball players. Rev Bras Cineantropom Desempenho Hum 2020, 22:e59831. D0l: http://dx.doi. org/10.1590/1980-0037.2020v22e59831

Copyright: This work is licensed under a Creative Commons Attribution 4.0 International License. 


\section{INTRODUCTION}

The evolution of basketball intensity in recent years is probably due to different variables, such as increase in the game pace and improvement in the physical conditions of players. The reality of basketball players is that they must express actions such as accelerations, decelerations, changes in direction, jumps, landings, contact with rivals, throws, passes, among others; and all of them, or at least many of them at high speed of execution and with large decision component ${ }^{1}$.

These high-intensity actions are expressions of strength that can be categorized as displacement strength, jumping strength, combat strength and throwing strength ${ }^{2}$. The jumping strength includes actions such as vertical jumps ${ }^{3,4}$ and landings; the displacement strength includes actions such as change of direction ${ }^{4,5}$, accelerations and decelerations ${ }^{4}$; the throwing strength includes all throws performed ${ }^{6}$ and, finally, the combat strength would be found in actions such as blocks, contacts in individual duels and rebound'.

Many of the movements in team sports require players to produce strength by influencing the eccentric and multidirectional phase, so it would be interesting to add a unilateral and multivectorial component to this type of sport to influence the eccentric phase of the movement. The vast majority of basketball actions or movements require three-dimensional deceleration and acceleration movements that require changes in direction, either in the horizontal or vertical vector ${ }^{6}$.

Therefore, strength training has acquired a fundamental role in the performance of basketball players. Traditionally, for strength training, resources such as free weights, machines, loads, obstacles, among others ${ }^{1}$, are used. In recent years, inertial technology has emerged as an alternative that enables accentuating the eccentric overload in more specific sports actions, such as changing direction, an essential aspect for player optimization, reducing the risk of injuries and in rehabilitation from injuries ${ }^{7}$. Currently, they have been considered as optimal methods for strength development, both for performance improvement, prevention and rehabilitation from injuries ${ }^{8-9}$.

Some of the effects of eccentric overload training described in literature are: improved intramuscular coordination, increased strength throughout ROM, less cardiovascular stress, compared to intense concentric contractions and greater muscle power and performance ${ }^{10}$. In addition, muscle fatigue generated by eccentric training causes, after its adequate rest, a protective effect that can remain several months after training ${ }^{11}$. This effect is commonly called the Repeated Bout Effect ${ }^{12}$ and its causes are multifactorial ${ }^{13}$.

The vast majority of actions in sport occur unilaterally. Traditionally, these skills have been optimized through bilateral actions ${ }^{14}$. On the other hand, different results have also been found ${ }^{8}$. Today, the direction in which strength is applied has become more important. In this way, the vertical component would produce actions such as jumps, the horizontal component would produce actions such as sprints and, finally, the lateral component would produce actions such as change of direction. 
A technology that helps optimizing the components mentioned above is the conical pulley, one of the inertial devices that allows working mainly on the horizontal component. This type of instrument showed improvements in change of direction and horizontal jump movements unilaterally performed $^{10}$, in addition to high specificity in sports gestures. Another inertial device is the ProSquat, Proinertial ${ }^{\circledR}$ which, although it simply limits the vertical component, facilitates the achievement of greater peaks of sport-specific strength. It was found that this instrument has improved performance especially in tests such as $\mathrm{CMJ}{ }^{15}$.

The aim of this study was to compare the effect of two different types of exercises on the jump height (countermovement jump) and on the 30 -meter linear sprint: a) half squat in the ProSquat Proinertial ${ }^{\circledR}$ machine, with a focus on providing maximum speed in the acceleration and deceleration phases in the last third of the movement to obtain higher level of eccentric overload in the area; and b) half traditional squat with free weight, ensuring that the execution speed is the maximum possible.

\section{METHOD}

\section{Sample}

The sample consisted of professional basketball players $(\mathrm{n}=8 ; 21.3$ years $\mathrm{DT}=3.45$, height $193.5 \mathrm{~cm}, \mathrm{DT}=8.04$ and weight $87.43 \mathrm{~kg}, \mathrm{DT}=11.65$ ). The inclusion criteria were to participate in weekly competitions and with 2 years of experience in strength training. Subjects were randomly assigned to a half squat program with eccentric overload $(n=4)$ and traditional squat program $(n=4)$.

\section{Procedure and Instruments}

Subjects were randomly assigned to a half squat program with eccentric overload $(n=4)$ and traditional squat program $(n=4)$. Training lasted 8 weeks and was carried out with regular group sessions. The first 2 weeks were used for assessments and for individuals to become familiar with exercises and inertial devices. For the next six weeks, subjects trained 1 day a week, 72 hours after the last game.

Tests included linear running and countermovement jumping (CMJ). Subjects were asked not to perform any strenuous exercise before tests and to rest well in the previous night.

The instrument used to evaluate the countermovement jump (CMJ) was the jump platform in software 1.8.0 (CHRONOJUMP ${ }^{\circledR}$, Software, Barcelona, Spain). The MySprintApp16 application was used to evaluate the 30-meter linear sprint.

30- $\mathrm{m}$ test: The subject was placed on the starting line, and when ready, he runs at maximum possible speed until completing the 30 meters of the linear sprint. It is recommended not to brake within a radius of 30 meters, but continue to apply maximum speed and brake afterwards. The test was performed three times, with a three-minute interval between attempts. 
CMJ test: In this jump, the athlete enters the platform with both hands on the hips. In a fast and continuous downward movement, he flex the knees at a $90^{\circ}$ flexion angle, maintaining the verticality of the torso and then generates the vertical jump that takes him off the ground. During the entire flight phase, the athlete must keep the lower limbs and trunk in full extension until contact with the platform. Landing should be performed in plantar flexion at the level of the ankle, knee and hip extension. The test was performed 5 times with 15 " of rest between jumps.

Programs lasted 8 weeks: 2 weeks of familiarization and 6 weeks of training. Players trained once a week and had a passive 3-minute recovery between sets. The load for week 1 and 2 was 4 series of 10 repetitions, weeks 3 and 4, 5 series of 10 repetitions and weeks 5 and 6, 6 series of 10 repetitions. The application of load in the traditional exercise was performed due to the nature of the effor $\mathrm{t}^{17}$, using 10 repetitions of 14 possible at maximum speed. Regarding the application of load in exercise with eccentric overload, half of the possible load allowed by the device (IM: $0.0332 \mathrm{~kg} * \mathrm{~m} 2$ ) was used, with concentric phase as fast as possible and focusing braking on the last third of the movement. The eccentric overload training was performed with the ProSquat, Proinertial ${ }^{\circledR}$ machine (Proinertial ${ }^{\circledR}$, Barcelona, Spain) by means of a series of half squats, while the group submitted to traditional training performed the same exercise, but with bar and discs.

Before performing the warm-up training exercises, athletes performed five minutes on a cycle ergometer, various mobility exercises, specific CORE exercises and activation of the lower body muscles using elastic bands.

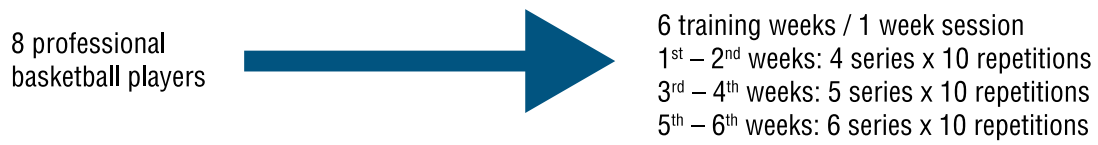

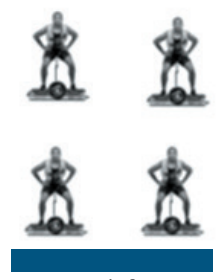

s1-2

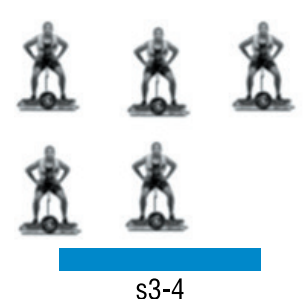

s3-4

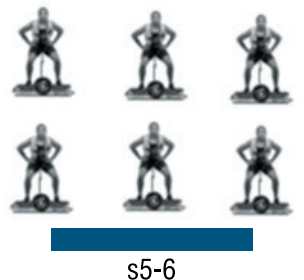

s5-6

Figure 1. Training procedure

\section{Data analysis}

Descriptive statistics was used to analyze the percentage of individual improvement in CMJ and 30-meter sprint. In addition, ANOVA for repeated samples was applied to determine the significant differences between pretest and post-test in both tests according to the type of training performed.

\section{RESULTS}

Depending on the type of training performed, significant improvements were observed in CMJ F $(1,6)=8.62$ test; $p=0.026$, and in the 30 -meter 
sprint $F(1,6)=11.12 ; p=0.016$, compared to pre-test. In both tests, the group that obtained the highest performance was the one that used eccentric overload: a) CMJ: (free weight: $\mathrm{M}=38.05 ; \mathrm{ST}=2.89$; $\mathrm{I} \mathrm{M}=43.27$, $\mathrm{ST}=1,65$ ); b) 30-meter sprint (free weight: $\mathrm{M}=4.38, \mathrm{ST}=0.22 ; \mathrm{I}: \mathrm{M}=$ $4.17, \mathrm{ST}=0.24)($ table 1$)$.

Table 1. Effect of eccentric overload on CMJ and 30-meter sprint of basketball players

\begin{tabular}{lcccc}
\hline & & \multicolumn{3}{c}{ Post-test } \\
\hline \multicolumn{1}{c}{$\mathrm{M}$} & $\mathrm{ST}$ & $\mathrm{F}(1,6)$ & $\mathrm{p}$ \\
\hline CMJ & & & & .026 \\
Free weight & 38.05 & 2.89 & 8.62 & \\
Yo-yo & 43.27 & 1.65 & & .016 \\
30-meter sprint & & & & \\
Free weight & 4.38, & .22 & 11.12 & \\
Yo-yo & 4.17 & .24 & & \\
\hline
\end{tabular}

Note. CMJ: countermovement jumps

\section{DISCUSSION}

In this study, in which exercises were compared only and exclusively in the vertical vector (half squat with free weight and half squat with eccentric overload), positive effects were obtained using both programs on dependent variables (CMJ and linear Sprint), with better results using eccentric overload. This occurred both in the horizontal and vertical vector, even with greater differences in the horizontal vector, as opposed to other investigations ${ }^{15}$.

For the CMJ test, significant improvements were found in the inertial squat group. These results were expected, since, when manifesting strength in the vertical component for this type of test, it is more specific. Similar results have already been found in similar investigations using this type of test ${ }^{15,18}$. The control group also showed improvements, because, when comparing traditional vertical and horizontal training, greater improvements were found in the group that trained vertically ${ }^{19}$.

In the sprint test, the inertial squat group showed significant improvements. Similar results were found in other investigations $s^{15,20,21}$. The control group did not show significant improvements, but lower limb adaptations had already been observed in other studies using traditional weight ${ }^{19}$. In literature, it has been shown that greater improvements reported for this test were obtained with the application of inertial technology to ischemic target muscles ${ }^{20}$. This may be due to the fact that higher power peak generated by the referred musculature reported higher level of performance for this test ${ }^{22}$.

\section{CONCLUSIONS}

Strength training for the development of specific actions related to displacement strength (linear sprint) and jumping strength (CMJ) are es- 
sential for the modern basketball player. Specialists have used different training programs (traditional training and use of isoinertial technology) that cause improvements in athletes' performance. In addition, it should be highlighted that squat training can generate positive cross-sectional effects for different specific actions in basketball.

\section{COMPLIANCE WITH ETHICAL STANDARDS}

\section{Funding}

This research did not receive any specific grant from funding agencies in the public, commercial, or non-profit sectors. This study was funded by the authors.

\section{Ethical approval}

This research is in accordance with standards set by the Declaration of Helsinki

\section{Conflict of interest statement}

The authors have no conflict of interests to declare.

\section{Author Contributions}

Conceived and designed the experiments: RC, JS, VM, AE. Performed the experiments: RC, JS, VM, AE. Analyzed data: RC, JS, VM, AE. Contributed with reagents/materials/analysis tools: RC, JS, VM, AE. Wrote the paper: RC, JS, VM, AE.

\section{REFERENCES}

1. Gonzalo-Skok O, Tous-Fajardo J, Arjol-Serrano J. L, Suarez-Arrones L, Casajús J. A, Mendez-Villanueva A. Improvement of Repeated-Sprint Ability and Horizontal-Jumping Performance in Elite Young Basketball Players with LowVolume Repeated-Maximal-Power Training. Int J Sport Physiol Perform 2016; 11(4):464-473.

2. Tous- Fajardo, J. Nuevas tendencias en fuerza y musculación. (J. Tous, Ed.). Barcelona; 1999

3. Alemdaroğlu U. The Relationship Between Muscle Strength, Anaerobic Performance, Agility, Sprint Ability and Vertical Jump Performance in Professional Basketball Players. J Hum Kinet 2012; 31(1):99-106.

4. Balsalobre-Fernández C, Nevado-Garrosa F, del Campo-Vecino J, GananciasGómez, P. Repetición de esprints y salto vertical en jugadores jóvenes de baloncesto y fútbol de élite. Apunt Educ Fis Deport 2015; 120(2):52-57.

5. Maroto-Izquierdo S, García-López D, de Paz JA. Functional and Muscle- Size Effects of Flywheel Resistance Training with Eccentric-Overload in Professional Handball Players. J Hum Kinet 2017; 60(1):133-143.

6. Struzik A, Pietraszewski B, Zawadzki J. Biomechanical Analysis of the Jump Shot in Basketball. J Hum Kinet 2014; 42(1):73-79.

7. Tous-Fajardo J, Gonzalo-Skok O, Arjol-Serrano JL, Tesch P. Enhancing changeof-direction speed in soccer players by functional inertial eccentric overload and vibration training. Int J Sport Physiol Perfor 2016;11(1): 66-73.

8. Berg HE, Tesch AA. gravity-independent ergometer to be used for resistance training in space. Aviat Space Environ Med 1994; 65(8):752-756. 
9. Jonsson P, Wahlström P, Öhberg L, Alfredson H. Eccentric training in chronic painful impingement syndrome of the shoulder: results of a pilot study. Knee Surg Sports Traumatol Arthrosc 2006;14(1):76-81.

10. Douglas J, Pearson S, Ross A, McGuigan M. Chronic adaptations to eccentric training: a systematic review. Sports Med 2017; 47(5):917-941.

11. Hortobagyi T, Hill JP, Houmard JA, Fraser DD, Lambert NJ, Israel RG. Adaptive responses to muscle lengthening and shortening in humans. J Appl Physiol 1996; 80(3):765-772.

12. Nosaka K, Sakamoto K, Newton M, Sacco P. How long does the protective effect on eccentric exercise-induced muscle damage last? Med Sci Sports Exerc 2001; 33(9):1490-1495.

13. Barroso R, Roschel H, Grinowitsch C, Araújo R, Nosaka K, Tricolia V. Effect of eccentric contraction velocity on muscle damage in repeated bouts of elbow flexor exercise. Appl Physiol Nutr Metab 2010;35(4):534-40.

14. Speirs D, Bennett M, Finn C, Turner A. Unilateral vs. Bilateral Squat Training for Strength, Sprints, and Agility in Academy Rugby Players. J Strength Cond Res 2016;30(2):389-392.

15. Gonzalo-Skok O, Tous-Fajardo J, Valero-Campo C, Berzosa C, Bataller AV, Arjol-Serrano JL, et al. Eccentric-Overload Training in Team-Sport Functional Performance: Constant Bilateral Vertical Versus Variable Unilateral Multidirectional Movements. Int J Sport Physiol Perform 2017; 12(7):951-958.

16. Romero-Franco N, Jiménez-Reyes P, Castaño-Zambudio A, Capelo-Ramírez F, Rodríguez-Juan JJ, González-HernándezJ, et al. Sprint perfomance and mechanical outputs computed with an iPhone app: Comparision with existing reference methods. Eur J Sport Sci 2017;17(4):386-392.

17. González Badillo JJ, Medina LS, Blanco FP, Rodríguez-Rosell D. La velocidad de ejecución como referencia para la programación, control y evaluación del entrenamiento de fuerza. Ergotech Consulting: Spain; 2017.

18. De Hoyo M, Pozzo M, Sañudo B, Carrasco L, Gonzalo-Skok O, DomínguezCobo S, Morán-Camacho E. Effects of a 10-Week In-Season Eccentric-Overload Training Program on Muscle-Injury Prevention and Performance in Junior Elite Soccer Players. Int J Sport Physiol Perform 2015; 10(1):46-52.

19. Arcos AL, Yanci J, Mendiguchia J, Salinero JJ, Brughelli M, Castagna, C. ShortTerm Training Effects of Vertically and Horizontally Oriented Exercises on Neuromuscular Performance in Professional Soccer Players. Int J Sport Physiol Perform 2014; 9(3):480-488.

20. Askling C, Karlsson J, Thorstensson A. Hamstring injury occurrence in elite soccer players after preseason strength training with eccentric overload. Scand J Med Sci Sports 2003; 13(4):244-250.

21. Tous-Fajardo J, Gonzalo-Skok O, Arjol-Serrano JL, Tesch P. Enhancing Changeof-Direction Speed in Soccer Players by Functional Inertial Eccentric Overload and Vibration Training. Int J Sports Physiol Perform 2016;11(1):66-73.

22. Chumanov ES, Heiderscheit BC, Thelen DG. The effect of speed and influence of individual muscles on hamstring mechanics during the swing phase of sprinting. J Biomech 2007; 40(16): 3555-3562.

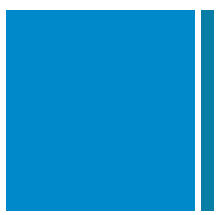

Corresponding author

Jorge Serna Bardavío

Partidada. Caparrella. INEFC

25192 Lleida (Spain)

973272022

E-mail: jserna@inefc.es 